\title{
RECA: proyecto y metodología
}

José Castiñeira Sánchez, Servicio de Investigación y Difusión del Patrimonio Histórico. D. G. de Bienes Culturales. Consejería de Cultura de la Junta de Andalucía

\section{La RECA nace como} resultado de una serie de avatares "heredados" más que fruto de un análisis y de una planificación previos
No podemos hablar de la Red de Espacios Culturales de Andalucía (RECA), y más concretamente sobre su significado como programa inserto en el "Plan Estratégico para la Cultura en Andalucía", sin realizar una reflexión acerca del camino recorrido hasta hoy por el singular patrimonio que integra esta Red, y las diferentes etapas de su gestión y tutela. Hemos de precisar que los bienes que integran la Red son de naturaleza diversa, predominando los yacimientos arqueológicos sobre los restantes bienes patrimoniales; así, mientras que contamos con sólo cinco monumentos entre los inmuebles que integran la RECA, los yacimientos arqueológicos son diecinueve. Por lo que respecta a su distribución geográfica, las provincias de Almería, Cádiz y Córdoba cuentan con cuatro, cada una de ellas; Granada, Málaga y Sevilla, con tres; Huelva, con dos; y Jaén con uno. Pero, debemos preguntarnos ¿Cómo se llega a esta composición y a esta distribución? Para responder, hay que hacer un poco de historia.

La administración cultural, a lo largo de la segunda mitad del siglo $X X^{1}$, adquirió una serie de inmuebles -fundamentalmente, predios rústicos- guiada por una doble intencio- nalidad. Por una parte, se trataba de ejercitar el grado máximo de protección que se puede llevar a cabo sobre un bien, esto es, adquirir su propiedad. Por otra, se compraron fincas, 0 partes de éstas, para que se pudieran llevar a cabo las excavaciones arqueológicas que realizaban equipos de investigadores, normalmente vinculados a universidades españolas. Todo ello nos ha conducido a la realidad actual. Por otra parte, la distribución geográfica desigual también tiene su explicación, ya que se adquirieron, sobre todo, aquellos yacimientos arqueológicos que revestían mayor interés para los citados investigadores universitarios. Por último, la Dirección General de Bellas Artes y Archivos, dependiente del Ministerio de Educación y Ciencia, se vio obligada a dotar de un servicio de guardería a muchos de los bienes adquiridos, especialmente aquellos en los que ya se habían exhumado elementos de gran valor histórico y artístico.

Una vez realizadas las transferencias de la administración estatal a la autonómica, se puso en marcha en 1986, por iniciativa de la Dirección General de Bellas Artes, el denominado "Plan especial de actuación en materia de bellas artes". Esta actuación llevó aparejado 


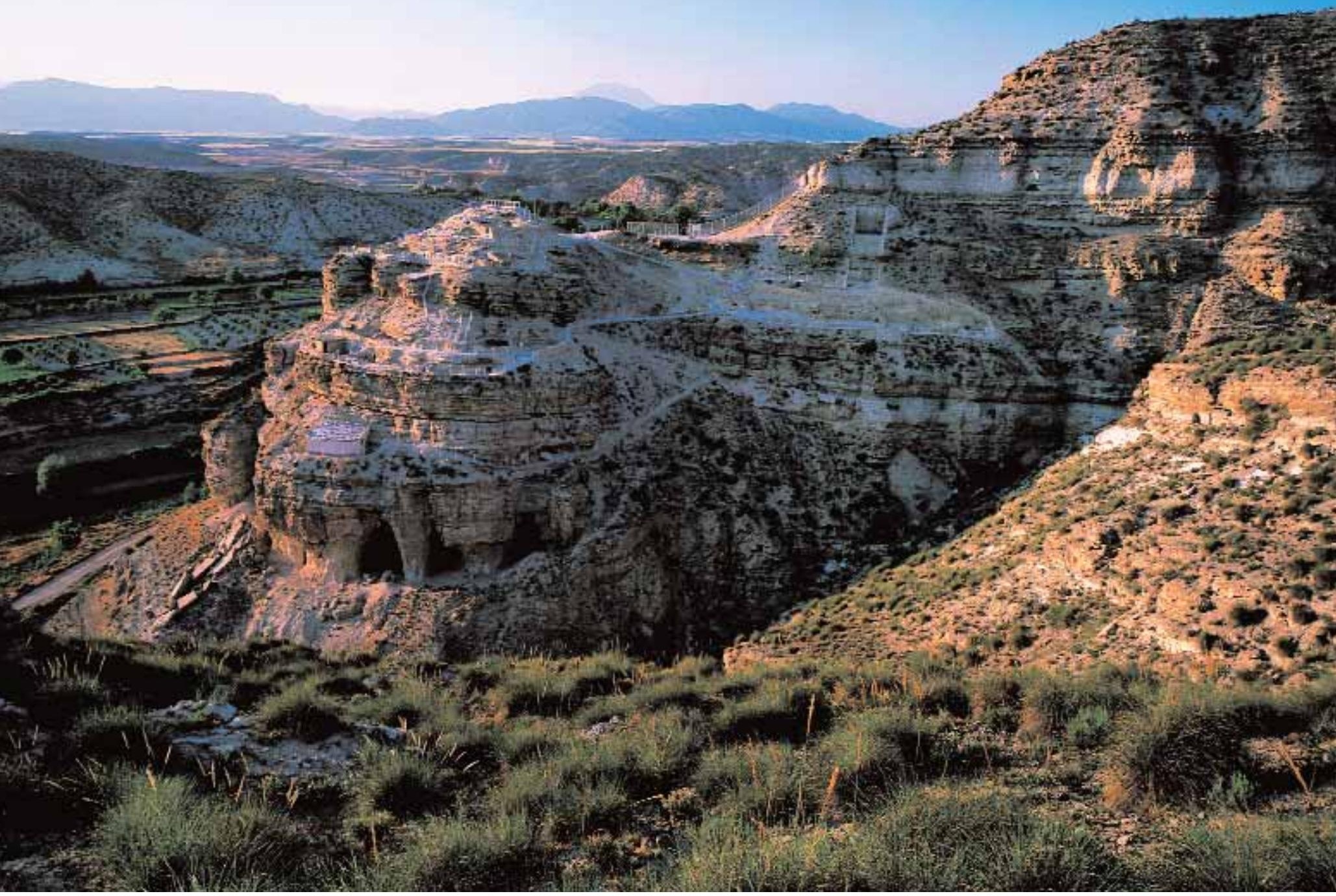




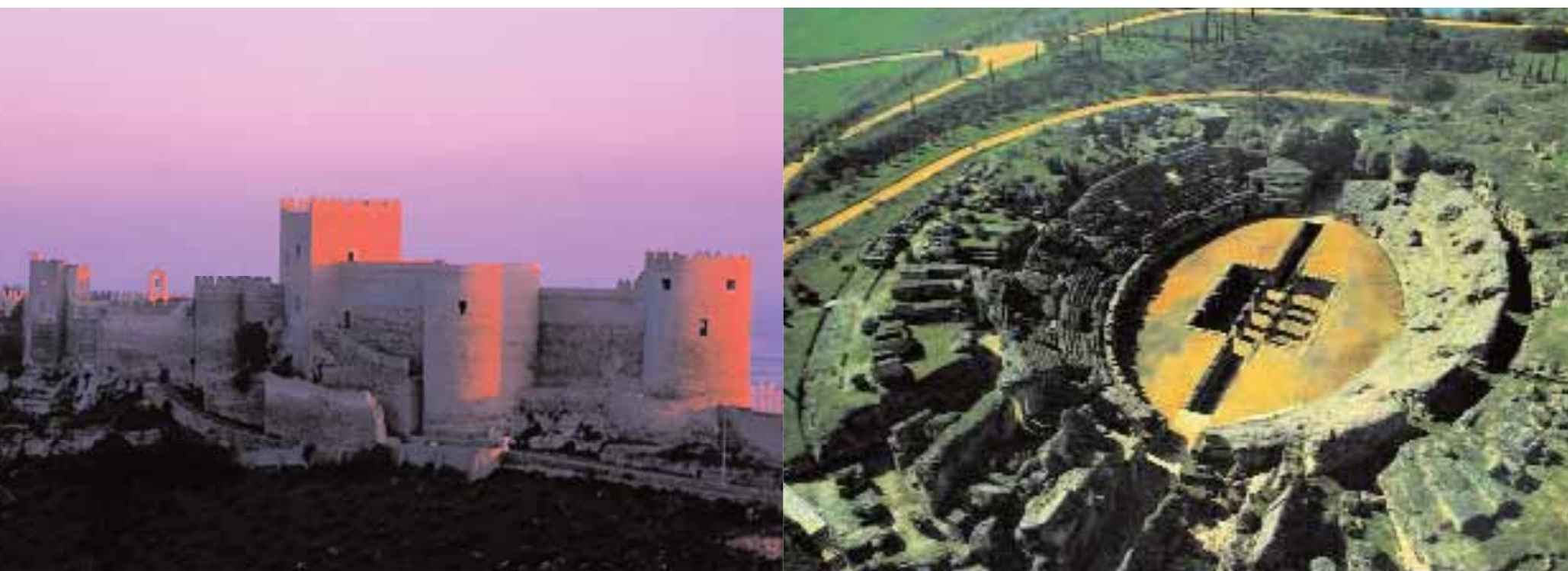

(1) Conjunto Arqueológico de la Alcazaba de Almería / CARLos de PAZ, D.G. DE BIeneS

(1) Conjunto Arqueológico de Itálica (Santiponce, Sevilla) / Guillermo Mendo, D.G. DE Bienes Culturales. Junta de Andalucía

el incremento en el número de guarderías, así como el reforzamiento de algunas de las existentes hasta la fecha.

Por último, la Junta de Andalucía ha realizado algunas adquisiciones, que complementan las ya realizadas por la administración estatal, al tiempo que se han incorporado bienes fruto de actuaciones de carácter urgente o preventivo, como es el caso de Cercadilla, en la capital cordobesa; así como las salazones romanas de Cádiz y de Almería.

En cuanto a los antecedentes inmediatos en la gestión de estos espacios, se ha de recordar que, cuando se crea la Dirección General de Instituciones del Patrimonio Histórico en 1996 todos los bienes inmuebles que estaban constituidos como unidades administrativas pasaron a depender de la misma; no así los yacimientos y resto de inmuebles que contaban únicamente con un sistema de guardería básica, y que continuaron adscritos a la Dirección General de Bienes Culturales. Ésta decidió entonces crear la denominada Red Andaluza de Yacimientos Arqueológicos (RAYA) para hacer más ágil, coherente y homogénea la gestión y la tutela de estos bienes patrimoniales que finalmente ha sido absorbido por la RECA. A esta red se incorporarían también diversos centros de interpretación dispersos por toda la geografía andaluza, y gestionados, en general, por los ayuntamientos.

En cuanto a los períodos históricos a los que pertenecen los bienes patrimoniales que conforman la RECA, cuatro de ellos son yacimientos prehistóricos, uno protohistórico, doce romanos, tres medievales y uno de la Edad Moderna. Tampoco es fruto de la casualidad la desproporción entre yacimientos romanos y el resto de los bienes. La solidez de muchas de las construcciones romanas -a pesar de encontrarse en estado de ruina, naturalmente-, frente a la fragilidad de los yacimientos prehistóricos o medievales, ha sido un factor determinante a la hora de posibilitar su permanencia al aire libre.

Este estado de cosas nos lleva a concluir que la RECA nace como resultado de una serie de avatares y circunstancias que podríamos calificar más como "heredados", que como el resultado de un análisis y de una planificación previos. Esta herencia se plasma en algunos desequilibrios y disfunciones de los que es 
a la red, de acuerdo con las orientaciones que inspiran el PECA. Por otra parte, y de acuerdo con la letra y el espíritu de iniciativas y programas tanto de la Consejería de Cultura como de otras administraciones, se deberá considerar en cada caso la potencialidad de cada bien patrimonial puesto en valor como motor de desarrollo local, evaluando su posible contribución a las industrias culturales, turísticas y derivadas. Se pretende además que la RECA no se gestione de modo autónomo, sino que se incorporen a redes ya existentes o por crear de carácter estatal y europeas.

Obviamente, se deberá contar con la colaboración y la participación de la administración local, en cada caso, para la mejor gestión de cada bien patrimonial; pero, además debemos sumarnos a todas esas iniciativas y programas que ya otras administraciones están poniendo en marcha y que, entre otros, cuentan con el patrimonio histórico como objeto de actuación. Nos referimos a iniciativas como la Ruta Bética Romana, que ya hoy día implica a más de una docena de ciudades en tres provincias andaluzas, y que es promovida desde la Consejería de Turismo, con la colaboración de ayuntamientos y Consejería de Cultura; la Nueva Estrategia para Andalucía (NERA), promovida desde la Consejería de Agricultura y Pesca, y que cuenta con el patrimonio histórico como uno de los factores para articular el desarrollo de las cincuenta áreas de actuación del programa; o la Consejería de Obras Públicas, que ya viene actuando desde hace décadas en el patrimonio histórico de nuestras poblaciones rurales a través del Programa de Espacios Públicos y por medio de la Empresa Pública del Suelo de Andalucía en colaboración con los ayuntamientos, entre otras.

Por último, no debemos olvidar que muchos bienes se localizan en espacios naturales incluidos en otra red, nos referimos a la Red de Espacios Naturales Protegidos de Andalucía (RENPA), gestionada por la Consejería de Medio Ambiente y que, amén de contar con una doble protección, pueden y deben contar con la capacidad de las dos conseje- rías para su puesta en valor y uso público, de acuerdo con los planes directores y de uso y gestión de los parques naturales. Las diputaciones provinciales tienen una gran oportunidad de actuar en muchas poblaciones 0 en comarcas, de la mano de la Consejería de Cultura y de la de Empleo, a través de mecanismos convenidos de gestión, utilizando como eje de la actuación al patrimonio histórico y de cara tanto a su recuperación como a su puesta en valor a través de la red. Un claro ejemplo de lo que se afirma aquí es la actuación "Viaje al tiempo de los iberos", donde participan la Diputación de Jaén y la Junta de Andalucía.

Dejaremos aquí los ejemplos, por no ser exhaustivos, pero son muchos más los organismos y administraciones que están llamados a colaborar en esta nueva etapa de gestión y de uso de estos bienes, tales como la Consejería de Empleo a través de sus Unidades Territoriales de Empleo, Desarrollo Local y Tecnológico, entre otras.

Además de los valores enunciados, el patrimonio histórico cuenta con otros de carácter inmaterial, tales como el simbólico y el educativo, que son imposibles de entender sin la participación de la ciudadanía, por ello se plantea, desde el inicio, estimular la participación de los habitantes de sus respectivos entornos, sin cuya colaboración difícilmente se conseguirán los objetivos propuestos con la creación de la RECA. La administración ha de responder a su confianza, extremando la gestión y la tutela de estos bienes, hasta lograr que se conviertan en referentes de las buenas prácticas en la gestión del patrimonio histórico dentro y fuera de Andalucía, así como lograr la excelencia en el ejercicio de la tutela.

\section{Nota}

${ }^{1}$ La excepción en el ámbito andaluz la constituye el Yacimiento Arqueológico de Itálica, cuyos expedientes de adquisición de terrenos se remonta mucho más atrás; si bien, fue en la década comprendida entre 1965 y 1975, en la que se llevaron a cabo la mayoría de las adquisiciones por parte de la administración del Estado. 


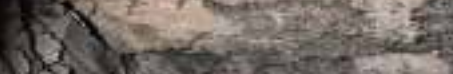

$2 \times$

(1) 3 $+3$

$\left\{\begin{array}{l}3,3 \\ 2,3\end{array}\right.$

3i. 38

ith

B.

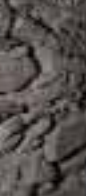

a)

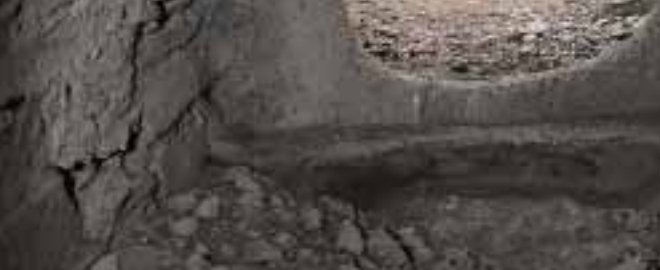

(8) Los Millares (Almería) / JuAn CARlos CAZALLA, IAPH

(ש) Doña Blanca (Puerto de Santa María, Cádiz) / ISABel Dugo, IAPH

(1) Cercadilla (Córdoba) / JuAn CARLos CAZALLA, IAPH
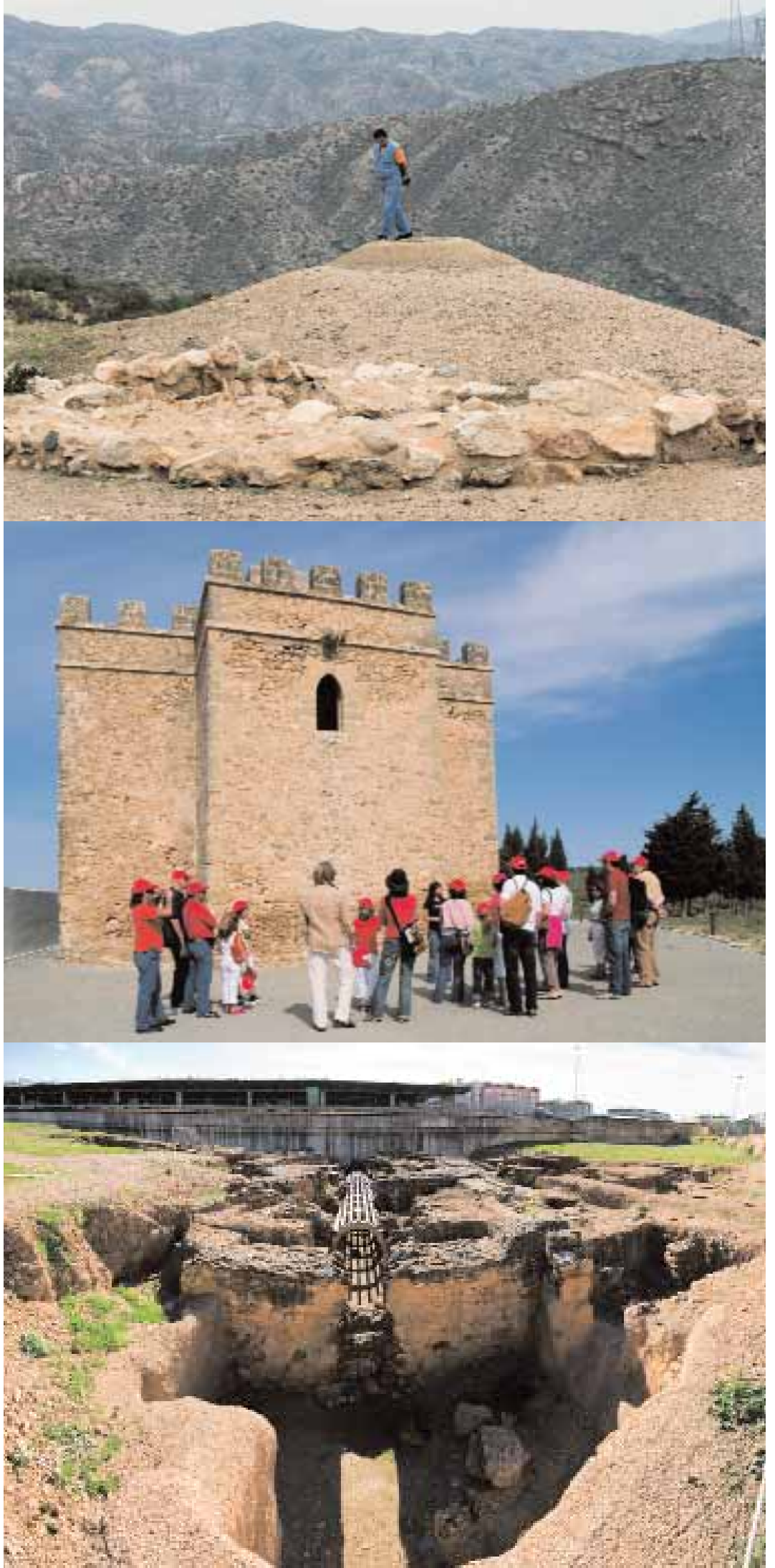